
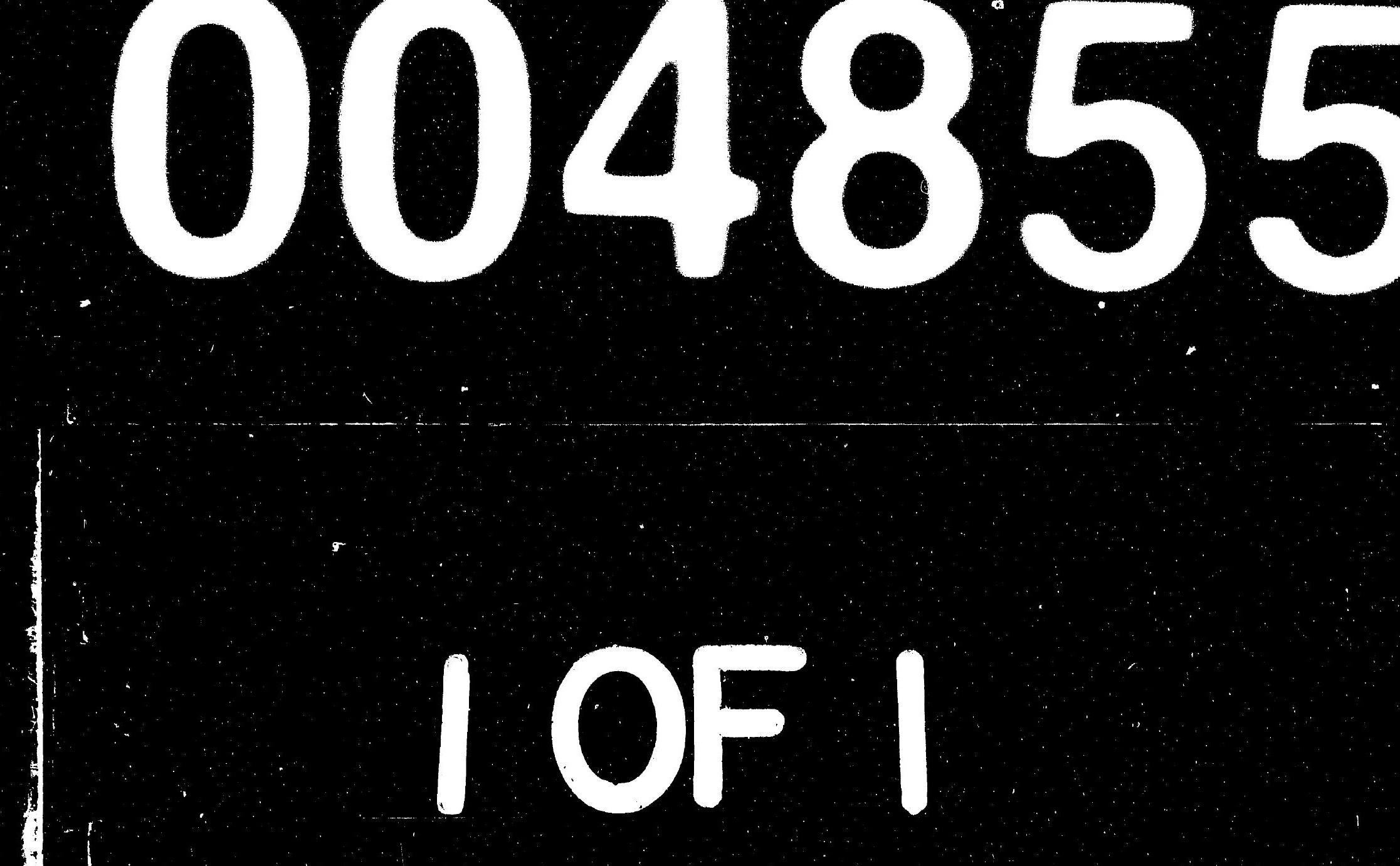

$\mid$ 


\title{
CALIBRATION OF THE FERMILAB E-704 POLARIZED TARGET*
}

\author{
D. A. Hill \\ High Energy Physics Division \\ Argonne National Lab, Argonne, IL 60439 \\ November 16, 1992 \\ ANL-HEP-TR--92-68 \\ DE93 004855
}

\section{A. Summary}

Table 1 lists the final, best estimate of the target polarization $\mathrm{P}_{\mathrm{T}}$ as a function of time for all of the periods during which scattering data were (or may have been) collected. The information under "RUN" refers to $\Delta \sigma_{\mathrm{L}}$-runs. The notation "sfs" stands for "start of frozen spin," "efs" for "end of frozen spin," " $\rightarrow$ la" for "go to large-aperture" target magnet position, and "nla" for "not large-aperture" position, i.e., the target magnet is in "polarizing" position. Where the "NOTE" column is blank it means that all standard frozen-spin conditions were in effect: the target temperature was reduced and the magnet was in large-aperture position. The timing marks were developed on the basis of three criteria: (1) the availability of direct NMR data, (2) the inclusion of major Target and Run boundaries, and (3) the arbitrary inclusion of enough "minor" Run boundaries to shorten large timing gaps.

The sign of the $\mathrm{P}_{\mathrm{T}}$-values is given in the NMR convention: $(+)$ corresponds to predominant occupation of the Zeeman ground state (the "thermal" NMR-signals are considered positive). Since the target magnet field pointed upstream, $(+)$ corresponds to target spin antiparallel to the beam momentum.

The estimated uncertainty on $\mathrm{P}_{\mathrm{T}}$ is $\pm 6.5 \%(2 \sigma)$, and the estimated uncertainty on the ratio of values for the two signs of polarization, $\mathrm{P}_{\mathrm{T}}(+) / \mathrm{P}_{\mathrm{T}}(-)$, is $\pm 4.3 \%(2 \sigma)$.

\section{B. Corrections to the thermal equilibrium NMR data}

The main tasks in establishing the target calibration are the consideration of potential systematic errors of the thermals measurements and the correction of such errors, where possible. This section describes systematics that have been identified as correctable offline.

A very large systematic effect was present during the first two days of twospin running. This was caused by a major readjustment that was made to the NMR system on 6-May-90 (increased damping of the tank circuits). A new set of thermals was taken on 13-May, and this information has been used to back-calibrate the online $\mathrm{P}_{\mathrm{T}}$-values for 11,12-May.

The online program that was used to convert the resistance thermometer readings to a temperature value used straight-line interpolation between the reference

*Work supported in part by the U. S. Department of Energy, Division of High Energy Phyșics, Contract No. W-31-109-ENG-38. 


\section{DISCLAIMER}

This report was prepared as an account of work sponsored by an agency of the United States Government. Neither the United States Government nor any agency thereof, nor any of their employees, makes any warranty, express or implied, or assumes any legal liability or responsibility for the accuracy, completeness, or usefulness of any information, apparatus, product, or process disclosed, or represents that its use would not infringe privately owned rights. Reference herein to any specific commercial product, process, or service by trade name, trademark, manufacturer, or otherwise does not necessarily constitute or imply its endorsement, recommendation, or favoring by the Urited States Government or any agency thereof. The views and opinions of authors expressed herein do not necessarily state or reflect those of the United States Government or any agency thereof. 
Table 1: Target polarization summary.

\begin{tabular}{|c|c|c|c|}
\hline DATE-TIME & RUN & $\mathrm{P}_{\mathrm{T}}$ & NOTE \\
\hline 11-May-0430 & & -.784 & sfs \\
\hline 1230 & 125 start & -.784 & \\
\hline 1540 & 127 end & -.784 & efs \\
\hline 1920 & & +.622 & nla \\
\hline 1940 & 129 start & +.657 & nla \\
\hline 1950 & & +.668 & nla \\
\hline 2010 & & +.685 & nla \\
\hline 2040 & 129 end & +.684 & sfs \\
\hline 2120 & 130 start & +.677 & \\
\hline $12-$ May- 0250 & 135 end & +.675 & \\
\hline 1000 & 141 start & +.673 & \\
\hline 1710 & 143 end & +.671 & \\
\hline 1800 & 144 start & +.671 & \\
\hline 2140 & 146 end & +.670 & \\
\hline 2330 & & +.669 & efs \\
\hline 15-May- 1620 & & -.829 & sfs \\
\hline 1650 & & -.821 & \\
\hline 2330 & 147 start & -.796 & \\
\hline 16-May-0650 & 153 end & -.793 & \\
\hline 1330 & 156 start & -.790 & \\
\hline 1930 & 160 start & -.788 & \\
\hline 17-May-0220 & 165 start & -.785 & \\
\hline 0850 & 169 end & -.782 & \\
\hline 0920 & & -.782 & efs \\
\hline 1650 & 170 start & +.759 & nla \\
\hline 1720 & 170 end & +.759 & sfs(nla) \\
\hline 1810 & 171 end & +.758 & nla \\
\hline 2300 & & +.751 & nla \\
\hline 2340 & 172 start & +.751 & nla \\
\hline $18-$ May-0200 & 175 start & +.749 & nia \\
\hline 0310 & & +.748 & nla \\
\hline 0440 & & +.750 & nla \\
\hline 0750 & & +.751 & nla \\
\hline 1010 & & +.748 & nla \\
\hline 1150 & & +.744 & nla \\
\hline 1650 & 185 start & +.743 & nla \\
\hline 2150 & 188 start & +.738 & nla \\
\hline 2230 & & +.738 & $\rightarrow \mathrm{a}$ \\
\hline
\end{tabular}

\begin{tabular}{rlll}
\hline \hline DATE-TIME & RUN & $P_{T}$ & NOTE \\
\hline 18-May-2340 & 188 end & +.737 & \\
19-May-0340 & 191 start & +.735 & \\
0850 & 195 end & +.732 & \\
1240 & 198 end & +.730 & \\
1400 & 199 start & +.729 & \\
1640 & 200 start & +.727 & \\
2230 & 203 end & +.724 & \\
20-May-0600 & 208 start & +.720 & \\
1430 & 213 end & +.715 & \\
1630 & 215 start & +.714 & \\
1830 & 216 end & +.713 & efs \\
1840 & 217 start & +.713 & nla \\
1930 & 218 start & +.729 & nla \\
2240 & 219 end & +.777 & nla \\
2320 & 220 start & +.780 & sfs \\
21-May-0200 & 223 start & +.771 & \\
0830 & 228 start & +.769 & \\
1420 & 231 end & +.767 & efs \\
22-May-0240 & & -.466 & nla \\
0300 & 234 start & -.549 & nla \\
0430 & 235 start & -.747 & nla \\
0600 & 235 end & -.806 & nla \\
0720 & 236 end & -.836 & sfs \\
0730 & 237 start & -.831 & \\
1240 & 239 end & -.827 & \\
1320 & 240 start & -.827 & \\
1940 & 243 start & -.824 & \\
23-May-0200 & 247 end & -.821 & \\
0800 & 251 end & -.818 & efs \\
5-Jun-0230 & 252 start & +.776 & nla \\
0330 & & +.784 & sfs(nla $)$ \\
0350 & 252 end & +.784 & nla \\
0520 & 253 end & +.785 & nla \\
1150 & & +.789 & nla \\
1450 & 254 start & +.783 & nla \\
1700 & 255 end & +.776 & nla \\
1810 & & +.772 & nla \\
1930 & 256 start & +.782 & nla \\
& & & \\
& & & \\
19 &
\end{tabular}




\begin{tabular}{|c|c|c|c|c|c|c|c|}
\hline DATE-TIME & RUN & $\mathrm{P}_{\mathrm{T}}$ & NOTE & DATE-TIME & RUN & $P_{T}$ & NOTE \\
\hline 5-Jun-2020 & 256 end & +.782 & nla & 11 -Jun-2100 & 343 end & -.780 & \\
\hline 2130 & & +.782 & $\rightarrow l a$ & 12-Jun-0200 & 348 end & -.779 & \\
\hline 6-Jun-0110 & 257 start & +.781 & & 0440 & 349 start & -.778 & \\
\hline 0550 & 259 end & +.780 & & 0650 & 350 end & -.777 & \\
\hline 0640 & "547" end & +.780 & & 1140 & & -.775 & \\
\hline 1200 & 261 start & +.779 & & 2000 & & -.772 & \\
\hline 1710 & 265 start & +.779 & & 13-Jun-0400 & & -.769 & \\
\hline 1840 & 266 end & +.778 & & 1200 & & -.766 & \\
\hline 2100 & 267 start & +.778 & & 2000 & & -.764 & \\
\hline 7-Jun-0200 & 270 start & +.777 & & 14-Jun-0400 & & -.761 & \\
\hline 0840 & 273 end & +.776 & & 1120 & 351 start & -.758 & \\
\hline 1410 & 277 end & +.775 & & 1850 & 355 end & -.755 & \\
\hline 1650 & & +.775 & efs & 15-Jun-0010 & 359 start & -.754 & \\
\hline & & -.707 & & 0550 & 362 end & -.752 & \\
\hline $\begin{array}{l}1920 \\
2010\end{array}$ & 279 start & $\begin{array}{l}-.101 \\
-.768\end{array}$ & nla & 0630 & 363 start & -.751 & \\
\hline $\begin{array}{l}2010 \\
2120\end{array}$ & $\begin{array}{l}279 \text { start } \\
280 \text { start }\end{array}$ & $\begin{array}{l}-.768 \\
-.800\end{array}$ & nla & 1430 & 369 end & -.748 & \\
\hline 2120 & & $\begin{array}{l}-.800 \\
-.794\end{array}$ & sfs & 1500 & 370 end & -.748 & \\
\hline 2200 & 285 start & & & 1540 & & -.748 & nla \\
\hline 8-Jun-0450 & & $\begin{array}{r}-.790 \\
785\end{array}$ & & 1720 & 371 start & -.746 & nla \\
\hline 1310 & 289 end & -.785 & & 2000 & 373 end & -.742 & nla \\
\hline 2010 & 297 end & -.781 & & 2330 & & -.737 & efs \\
\hline 9-Jun-0350 & 302 end & -.776 & & & & & \\
\hline 0520 & 303 start & -.776 & & 16-Jun-0250 & 374 start & +.805 & nla \\
\hline 1200 & 308 start & -.772 & & 0310 & 375 start & +.805 & sfs \\
\hline 1620 & 310 end & -.769 & & 0340 & 377 start & +.799 & \\
\hline 1650 & 311 end & -.769 & efs & 0850 & 380 end & +.795 & \\
\hline 10-Jun-0550 & & +.751 & la & 1430 & 383 end & +.790 & \\
\hline 0640 & 319 start & $\begin{array}{l}+.151 \\
+.765\end{array}$ & mia & 1810 & 384 start & +.787 & \\
\hline 0710 & & $\begin{array}{l}+.105 \\
+.772\end{array}$ & $\begin{array}{l}\text { nla } \\
\text { nla }\end{array}$ & 17-Jun-0030 & 387 end & +.781 & \\
\hline 0740 & & +.774 & sfs & 0730 & 392 start & +.775 & \\
\hline 0800 & 320 start & +.774 & & 1210 & & +.771 & \\
\hline 1450 & 325 start & +.774 & & 1350 & 395 end & +.770 & efs \\
\hline 2240 & 328 end & +.774 & & 1810 & 399 start & -.801 & sfs \\
\hline 11-Jun-0010 & 329 end & +.774 & efs & 1820 & & -.798 & \\
\hline & & -.722 & & 2150 & 400 start & -.792 & \\
\hline 0150 & $\begin{array}{l}330 \text { start } \\
330 \text { end }\end{array}$ & $\begin{array}{l}-.722 \\
-.784\end{array}$ & & 18-Jun-0310 & 402 end & -.790 & \\
\hline 0210 & 331 start & -.793 & sfs & 0840 & 405 end & -.787 & \\
\hline 0225 & & -.792 & & 1210 & 407 end & -.785 & \\
\hline 0720 & 336 start & -.785 & & 2000 & & -.781 & \\
\hline 1410 & 339 end & -.783 & & 19-Jun-0400 & & -.776 & \\
\hline 1530 & 340 start & -.782 & & 1220 & & -.772 & \\
\hline & & & & 1800 & & -.769 & efs \\
\hline
\end{tabular}




\begin{tabular}{|c|c|c|c|c|c|c|c|}
\hline DATE-TIME & RUN & $P_{T}$ & NOTE & DATE-TIME & RUN & $P_{T}$ & NOTE \\
\hline 20-Jun-0310 & & +.721 & nla & 26-Jun-0750 & 494 end & -.809 & \\
\hline 0450 & 408 start & +.759 & nla & 1300 & & -.806 & \\
\hline 0610 & 408 end & +.770 & sfs & 1810 & 495 start & -.804 & \\
\hline 0700 & 409 start & +.764 & & 27-Jun-0150 & 499 end & -.800 & \\
\hline 0900 & & +.762 & (nla) & 1040 & 506 end & -.796 & \\
\hline 1400 & 412 start & +.761 & & 1210 & 507 start & -.795 & \\
\hline 1910 & 415 end & +.759 & & 1440 & 508 end & -.794 & \\
\hline 2120 & 416 start & +.758 & & 1.950 & 509 start & -.791 & \\
\hline 21-Jun-0210 & 418 end & +.757 & & 2200 & 510 end & -.790 & \\
\hline 0730 & 422 end & +.755 & & 2220 & & -.790 & efs \\
\hline 0930 & 424 start & +.754 & & 2350 & 511 start & +.275 & nla \\
\hline 1740 & 428 end & +.751 & & 28 -Jun-0200 & & +.760 & nla \\
\hline 1810 & & +.751 & efs & 0210 & 511 end & +.761 & nla \\
\hline 23-Jun-0930 & 450 start & -.356 & nla & 0230 & 512 start & +.764 & nla \\
\hline 1100 & 451 start & -.512 & nla & 0300 & 513 start & +.765 & sfs \\
\hline 1240 & 452 start & -.603 & nla & 0310 & & +.762 & \\
\hline 1320 & 453 start & -.616 & nla & 0350 & & +.753 & \\
\hline 1420 & 454 start & -.640 & nla & 1140 & 518 end & +.750 & \\
\hline 1530 & & -.662 & nla & 1230 & 519 start & +.750 & \\
\hline 1600 & 454 end & -.672 & sfs & 1820 & 522 start & +.747 & \\
\hline 1620 & 45.5 start & -.660 & & 29-Jun-0020 & 526 start & +.745 & \\
\hline 2140 & 458 start & -.657 & & 0750 & 530 end & +.743 & \\
\hline 24-Jun-0430 & 462 start & -.654 & & 1240 & 531 start & +.741 & \\
\hline 1200 & 465 end & -.650 & & 1930 & 536 start & +.738 & \\
\hline 1830 & 469 end & -.647 & & 30-Jun-0200 & 539 end & +.736 & \\
\hline 2140 & & -.645 & & 0300 & 540 start & +.736 & \\
\hline 25-Jun-0000 & 472 end & -.644 & efs & 0800 & 542 end & +.734 & \\
\hline 0040 & 473 start & & & 0920 & 543 start & +.734 & \\
\hline 0210 & $\begin{array}{l}473 \text { start } \\
473 \text { end }\end{array}$ & $\begin{array}{l}--.124 \\
-.809\end{array}$ & $\begin{array}{l}\text { nla } \\
\text { sfs }\end{array}$ & 1120 & 545 start & +.733 & \\
\hline 0350 & 474 end & $\begin{array}{l}-.809 \\
-.799\end{array}$ & sts & 1300 & 546 start & +.732 & \\
\hline 0520 & 475 end & $\begin{array}{l}-.199 \\
-.797\end{array}$ & efs & 1840 & 546 end & +.730 & \\
\hline & & & & 1-Jul-0230 & 551 end & +.727 & \\
\hline 0600 & $476=$ tart & -.230 & nla & 0910 & 554 end & +.725 & \\
\hline 0720 & 477 start & -.604 & nla & 1200 & 556 end & +.724 & efs \\
\hline 0810 & & -.751 & nla & 1510 & & -.798 & sfs \\
\hline 0840 & 478 start & -.795 & nla & 1530 & 557 start & -.794 & \\
\hline 1000 & 479 end & -.824 & sfs & 2010 & 559 start & -.793 & \\
\hline 1130 & 480 start & -.819 & & 2-Jul-0220 & 560 end & -.787 & \\
\hline 1520 & 485 end & -.817 & & 0810 & 562 end & -.782 & \\
\hline 1540 & 486 start & -.817 & & 0820 & & -.782 & efs \\
\hline
\end{tabular}


points of the lookup table. Offline curve fitting of the table shows that the online temperature values used in conjunction with the thermals should be reduced by typically $1-2 \%$, depending on the exact temperature. This correction has been applied to each set of thermals data.

On a few occasions during the two-spin runs, gross instabilities and offsets were observed in the thermometer readout system. Eventually it was noticed that these periods of instability were invariably associated with times of very high humidity in the experimental hall. It appeared that if the ambient humidity rose above some threshold value the readout became unreliable. By the end of the two-spin running period the problem had been traced to some sensitive element(s) on the thermometry amplifier board, and a solution was found, which consisted of spraying the board with a sealant. This solution came too late, however, to ensure the integrity of any of the E-704 thermals data. As will be seen in Sec. C, the sets of thermals taken at various times are mutually consistent, except for the set of 19-June. For this set, the size of the thermal NMR signals was reasonable but the indicated temperature of the beads was higher than normal by $>10 \%$. There was no known reason for the dilution refrigerator to equilibrate at a different temperature on this occasion. This, and other internal evidence, strongly suggested that the thermometry was subject to a "humidity error" during that set, and that set of thermals was not used for the online running. It will also be excluded in the final offline analysis, although the data are included in the next section for completeness.

In an unrelated development, by the time that the final set of thermals data was taken on 2-July, a problem with temperature "bursts" of the dilution refrigerator had become so severe that there was concern that a reliable value of temperature could not be assigned for that set. Offline modelling of the spin dynamics shows that this error is very unlikely to be $>1 \%$, and a small $(+0.87 \%)$ temperature correction has been applied to that set for this effect. Also, it should be noted that the thermometry system was recalibrated on 21-June. Because of a different setting of the "offsets," a different algorithm has been used to obtain the offline estimate of the temperature for the 2-July thermals.

Finally, there is a question about the possible heating effect of noise and pickup currents in the thermometer resistors. During the running period, tests suggested that the "beads" thermometer was reading as much as $100 \%$ high during the frozenspin periods i.e., $\approx 100 \mathrm{mK}$ instead of $\approx 50 \mathrm{mK}$ ) owing to heating from spurious ac currents. There is no particular reason to believe that these pickup currents were not also present during thermals measurements. However, since the thermals were taken at temperatures near $1 \mathrm{~K}$, and since it is well known that the thermal boundary resistance (Kapitsa effect) is a steep function of teinperature (boundary resistance $\propto T^{-n}$, where $n \geq 3$ ), it is clear that the heating effect for the thermals data is $\ll 1 \mathrm{mK}$ and is thus entirely negligible. 


\section{Thermals data}

The calibration coefficient for $\mathrm{P}_{\mathrm{T}}$ is inversely proportional to a quantity $A T$, where $A$ is the integrated surface area of the thermal NMR signal and $T$ is the bead temperature during the thermals measurement. Table 2 lists the thermals data acquired online, along with the offline values resulting from the above systematic corrections. The Signal Area values are labeled with NMR coil numbers. Coil No. 1 is at the upstream end of the target, No. 3 at the downstream end. (A coil provided at the middle of the target was inoperative.) Note that the statistical error corresponds to a $2 \sigma$ value.

Table 2: Thermal equilibrium data.

\begin{tabular}{|c|c|c|c|c|c|}
\hline \multirow[b]{3}{*}{ Date } & \multicolumn{2}{|c|}{ Online Data } & \multicolumn{3}{|c|}{ Offline Values } \\
\hline & \multicolumn{2}{|c|}{ Signal } & \multicolumn{3}{|c|}{ Statistical } \\
\hline & Area & $T(\mathrm{~K})$ & $T(\mathrm{~K})$ & $A T$ & Error $(2 \sigma)$ \\
\hline \multirow[t]{4}{*}{ 6-May } & $A_{1}=17416$ & 0.998 & & & \\
\hline & $A_{3}=14974$ & 0.998 & & & \\
\hline & (used until & 3-May) & & & \\
\hline & (new dan & ping) & & & \\
\hline \multirow[t]{7}{*}{ 13-May } & $A_{1}=6271$ & 1.049 & 1.038 & 6509 & 25 \\
\hline & $A_{3}=4183$ & 1.049 & 1.038 & 4342 & 28 \\
\hline & (retur & & & & \\
\hline & $A_{1}=6278$ & 1.047 & 1.036 & 6504 & 50 \\
\hline & $A_{3}=4164$ & 1.047 & 1.036 & 4314 & 75 \\
\hline & (used until & 1-May) & & & \\
\hline & (retur & & & & \\
\hline \multirow[t]{3}{*}{ 31-May } & $A_{1}=6183$ & 1.065 & 1.040 & 6430 & 65 \\
\hline & $A_{3}=4017$ & 1.065 & 1.040 & 4178 & 81 \\
\hline & (used until & 2-July) & & & \\
\hline \multirow[t]{3}{*}{ 19-June } & $A_{1}=6053$ & 1.228 & 1.192 & 7215 & 78 \\
\hline & $A_{3}=4015$ & 1.228 & 1.192 & 4786 & 71 \\
\hline & $($ not $\mathrm{u}$ & & & not us & ed) \\
\hline \multirow[t]{2}{*}{ 2-July } & $A_{1}=5864$ & 1.057 & 1.104 & 6471 & 60 \\
\hline & $A_{3}=3883$ & 1.042 & 1.089 & 4230 & 89 \\
\hline
\end{tabular}

Examination of the offline-corrected values of $A T$ leads one to the conclusion that, with the exception of the 19-June thermals already noted previously, the NMR system was reasonably stable over the two-spin running period. The extent to which 
Table 3: Offline correction coefficients for $\mathrm{P}_{\mathrm{T}}$.

\begin{tabular}{ll}
\hline \hline Dates applicable & Offline multiplier \\
\hline 11-May to & $M_{1}=0.998(17416) /[1.038(6271)]=2.670 \pm 0.010$ \\
13-May & $M_{3}=0.998(14974) /[1.038(4183)]=3.442 \pm 0.022$ \\
13-May to & $M_{1}=1.047 / 1.036=1.011 \pm 0.008$ \\
31-May & $M_{3}=1.047 / 1.036=1.011 \pm 0.018$ \\
31-May to & $M_{1}=1.065 / 1.040=1.024 \pm 0.010$ \\
19-June & $M_{3}=1.065 / 1.040=1.024 \pm 0.020$ \\
19-June to & $M_{1}=1.065(6183) /[1.104(5864)]=1.018 \pm 0.009$ \\
2-July & $M_{3}=1.065(4017) /[1.089(3883)]=1.011 \pm 0.021$ \\
\hline
\end{tabular}

some of the error bars do not overlap is fairly typical of the "drift" experienced with this type of system for these kinds of time intervals.

Using the information in Table 2, the offline correction coefficients (multipliers,

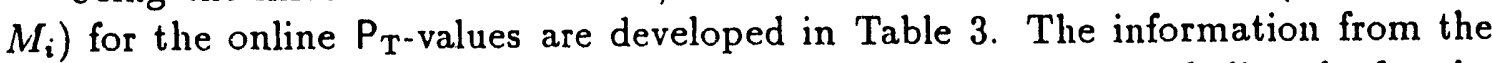
thermals sets of 13-May (second set) and 31-May has been used directly for the respective subsequent running periods. The information from 13-May (first set, before the NMR retune) has been used retrospectively for the earliest runs, and the information from 2-July has been used retrospectively back to 19-June. The 19-June data have been rejected both online and offline, as noted in Sec. B. With the exception of the first two days of data-taking, there are only modest deviations from unity. For a major part of the running time (13-May to 19-June), the only correction applied is that for the "curvature" of the thermometer lookup table. The only uncertainties included here on the $\mathrm{M}_{i}$ are the $2 \sigma$ sampling errors carried forward from Table 2.

\section{Maximum polarizations}

Examination of the maximum polarizations attained for each NMR coil, on various occasions, can give some idea of the overall relative consistency of the results and also of the uniformity of the polarization within the target. Table 4 lists the values of polarization attained in both coils at the beginning of selected frozen-spin series. The online values have been corrected with the $\mathrm{M}_{i}$ of Table 3 . The following conclusions can be drawn from these data:

1. There are no evident gross trends as a function of time. The fluctuations among the values corresponding to different occasions are probably mainly due to such factors as differences in the times allotted for the polarization 
Table 4: Maximum attained polarizations for each coil.

\begin{tabular}{|c|c|c|}
\hline DATE & $P_{1}$ & $P_{3}$ \\
\hline 11-May & -.788 & -.781 \\
\hline 14 & +.801 & +.809 \\
\hline 15 & -.835 & -.822 \\
\hline 17 & +.751 & +.767 \\
\hline 20 & +.774 & +.787 \\
\hline 22 & -.840 & -.831 \\
\hline 5-June & +.780 & +.788 \\
\hline 7 & -.823 & -.777 \\
\hline 10 & +.778 & +.770 \\
\hline 11 & -.798 & -.787 \\
\hline 16 & +.798 & +.813 \\
\hline 17 & -.807 & -.796 \\
\hline 20 & +.778 & +.763 \\
\hline 25 & -.822 & -.826 \\
\hline 28 & +.766 & +.764 \\
\hline 1-July & -.797 & -.800 \\
\hline
\end{tabular}

buildup, differing degrees of experience of the target operators, and differing degrees of "plugging" of the refrigerator.

2. The mean value for negative $P_{T}$ is $\langle P(-)\rangle=-0.808 \pm 0.005$, and for positive, $\langle P(+)\rangle=+0.780 \pm 0.005$, where the uncertainties are $1 \sigma$. The difference is consistent with our online experience that slightly greater negative values could be attained for a given amount of effort.

3. The mean absolute value for coil 1 is $\left\langle\left|P_{1}\right|\right\rangle=0.796 \pm 0.006$, and for coil 3 , $\left\langle\left|P_{3}\right|\right\rangle=0.793 \pm 0.006$. Thus, there is no significant difference between the target ends, on the whole. However, there are individual instances where the end-values were significantly different, such as on 7-June and on 23-June (the latter case has not been included in Table 4).

\section{E. Treatment of frozen-spin data from coil 1}

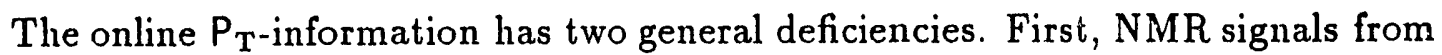
both coils were not always taken at the end of frozen-spin running, after returning the target magnet to the nla position. On some occasions, neither coil was registered. Second, examination of the complete data set indicates that a measurable fraction of 
the $\mathrm{P}_{\mathrm{T}}$-decay during frozen-spin usually occurred right at the beginning, i.e., while the dilution refrigerator was cooling down. These deficiencies are partially offset by the fact that coil-1 data were taken at fairly regular intervals during the frozen-spin condition. (Since the magnet $z$-offset was $\approx 15 \mathrm{~cm}$, coil 1 , but not coil 3 , remained in a reasonably uniform field during frozen-spin.) In principle, these data can be used to help fill in the missing records, but it is necessary to ascertain that there is no systematic discrepancy between the two types of coil-1 data.

The online record does contain a number of instances in which, near the end of a frozen-spin period, proximate data were taken for both frozen-spin (la) and polarizing ( $\mathrm{nla}$ ) positions, for coil 1. Averages of these cases give the following results:

$$
\begin{aligned}
& \left\langle P_{1}(\text { la }) / P_{1}(\text { nla }),(-)\right\rangle=1.0036 \pm 0.0028 \\
& \left\langle P_{1}(\text { la }) / P_{1}(\text { nla }),(+)\right\rangle=1.0035 \pm 0.0024 \\
& \left.\left\langle P_{1}(\text { la }) / P_{1} \text { (nla }\right), \text { all }\right\rangle=1.0036 \pm 0.0017
\end{aligned}
$$

where the uncertaitities are $1 \sigma$. The ratio does not depend on the sign of the polarization and is barely significantly different from unity.

\section{F. Comparison of overall decay rates for the two coils}

The online record has several instances in which coil 3 was not registered at the end of frozen-spin. Since the best estimate of $P_{T}$ is the mean of the two end-values, it is desirable to see if the missing coil- 3 records can be estimated from the available coil-1 data combined with the coil-3 measurements taken at the start of frozen-spin. The basic issue here is the relationship between the polarization decay rates for the two coils.

Table 5 lists the ten instances throughout E-704 in which NMR data for both coils is available for both sfs and efs. The time interval between sfs and efs is $\Delta t$. The polarization decay rate for each coil is estimated as the logarithmic derivative. Although there is a lot of scatter in the rates, it is clear by inspection that there is a fair degree of correlation between the rates for the two coils. Furthermore, the mean rates for the two coils do not differ significantly: $\left\langle-\Delta P_{1} / P_{1} \Delta t\right\rangle=2.03 \pm 0.41 \% /$ day, and $\left\langle-\Delta P_{3} / P_{3} \Delta t\right\rangle=2.01 \pm 0.38 \% /$ day; $_{\text {; }}$ where the uncertainties are $1 \sigma$ and the two cases with $\Delta t<0.7$ day have been excluded. The implication is that the decay rate observed for coil 1 is a good predictor of the coil-3 rate. This is actually a bit surprising, if true, since the "holding" fields at the ends of the target differ substantially ( $2.5 \mathrm{~T}$ at coil $1 \mathrm{vs} \approx 2.0 \mathrm{~T}$ at coil 3 ), and the decay rate is expected to be approximately inversely proportional to the field at these temperatures. Of course, this expected dispersion could easily be masked by the uncertainties.

If it is assumed that the data for the two coils can be binned together, the combined mean decay rate is $\left\langle-\Delta \mathrm{P}_{\mathrm{T}} / \mathrm{P}_{\mathrm{T}} \Delta t\right\rangle=2.02 \pm 0.26 \% /$ day. 
Table 5: Polarization decay rates based on sfs, efs measurements.

\begin{tabular}{rccccccc}
\hline \hline & \multicolumn{2}{c}{$\mathrm{P}_{1}$} & \multicolumn{2}{c}{$\mathrm{P}_{3}$} & \multicolumn{2}{c}{$\Delta t$} & $-\Delta \mathrm{P}_{1} / \mathrm{P}_{1} \Delta t$ \\
DATE & sfs & efs & sfs & efs & $($ days $)$ & $(\% /$ day $)$ & $(\% /$ day $)$ \\
\hline 11-May & -.788 & -.782 & -.781 & -.781 & 0.465 & 1.64 & 0.00 \\
11-12-May & +.684 & +.673 & +.685 & +.664 & 1.118 & 1.44 & 2.74 \\
15-17-May & -.835 & -.791 & -.822 & -.773 & 1.708 & 3.09 & 3.49 \\
5-7-June & +.780 & +.772 & +.788 & +.778 & 2.555 & 0.40 & 0.50 \\
10-11-June & +.778 & +.776 & +.770 & +.771 & 0.688 & 0.37 & -0.19 \\
11-15-June & -.798 & -.746 & -.787 & -.750 & 4.563 & 1.43 & 1.03 \\
16-17-June & +.798 & +.760 & +.813 & +.779 & 1.444 & 3.30 & 2.90 \\
25-27-June & -.822 & -.788 & -.826 & -.793 & 2.514 & 1.65 & 1.59 \\
28-June- & & & & & & & \\
1-July & +.766 & +.725 & +.764 & +.724 & 3.375 & 1.59 & 1.55 \\
1-2-July & -.797 & -.778 & -.800 & -.787 & 0.715 & 3.33 & 2.27 \\
\hline \hline
\end{tabular}

\section{G. Frozen-spin polarization decay rates for coil 1}

As mentioned previously, it appears that there was a measurable transient decay at the onset of frozen-spin conditions. It is of interest to derive decay rates from the post-sfs data taken at various intervals for coil 1, selecting only data points taken $\approx 20 \mathrm{~min}$ or more after the establishment of frozen-spin. The result of such an exercise is shown in Table 6 . The decay rate is obtained by a linear regression analysis on the indicated number of points $n$ for each case. Here, again, $\Delta t$ is the total time spanned. The mean values are:

$$
\begin{aligned}
& \text { decay rate }(-)=1.61 \pm 0.18 \% / \text { day, } \\
& \text { decay rate }(+)=1.37 \pm 0.33 \% / \text { day, } \\
& \text { decay rate }(\text { all })=1.51 \pm 0.16 \% / \text { day, }
\end{aligned}
$$

where the uncertainties are $1 \sigma$ and the two cases with $\Delta t<0.7$ day have again been excluded. The $(-,+)$ rates do not differ significantly. The combined mean decay rate is significantly smaller than the rates derived in Sec. F, which included the effect of initial transients.

Comparison of this decay rate with previously published values is made difficult by the fact that there are very few examples of frozen-spin at $2.5 \mathrm{~T}$. The measurement by de Boer and Niinikoski [NIM 114, (1974) 495] would give the above decay rate at a temperature of $50-60 \mathrm{mK}$, but that is for a propanediol target. Bernard et al. [NIM A249, (1986) 176] have measured 1-pentanol (the same material as for E-704) up to fields of $\approx 0.5 \mathrm{~T}$. Plausible extrapolation of their values would yield 
Table 6: Coil-1 polarization decay rates excluding the initial transient.

\begin{tabular}{lccccc}
\hline \hline $\begin{array}{l}\text { Date } \\
\text { (efs) }\end{array}$ & $\begin{array}{c}\text { Target } \\
\text { sign }\end{array}$ & $n$ & $\begin{array}{c}\Delta t \\
\text { (days) }\end{array}$ & $\begin{array}{c}\text { Correlation } \\
\text { coefficient }\end{array}$ & $\begin{array}{c}\text { Decay rate } \\
(\% / \text { day })\end{array}$ \\
\hline 12 -May & + & 7 & 1.090 & 0.907 & 1.11 \\
17 & - & 7 & 1.410 & 0.989 & 1.21 \\
20 & + & 18 & 2.813 & 0.980 & 1.79 \\
21 & + & 3 & 0.514 & 0.9995 & 1.02 \\
23 & -- & 6 & 1.020 & 0.947 & 1.32 \\
7 -June & + & 15 & 0208 & 0.533 & 0.47 \\
9 & - & 9 & 1.784 & 0.930 & 1.74 \\
11 & + & 4 & 0.674 & -0.429 & -0.73 \\
15 & - & 21 & 4.347 & 0.965 & 1.09 \\
17 & + & 8 & 1.423 & 0.936 & 2.58 \\
19 & - & 8 & 1.840 & 0.979 & 1.61 \\
21 & + & 10 & 1.465 & 0.941 & 1.12 \\
25 & - & 7 & 1.319 & 0.997 & 1.86 \\
27 & - & 14 & 2.452 & 0.993 & 1.44 \\
$1-J u l y$ & + & 18 & 3.340 & 0.993 & 1.13 \\
2 & - & 5 & 0.701 & 0.983 & 2.61 \\
\hline \hline
\end{tabular}

a temperature of $110 \mathrm{mK}$ or higher for the above decay rate. It is worth noting that the entries of 15 -June and 1 -July in Table 6 , which are potentially the most accurate owing to the long times spanned, have rates that are noticeably less than the global mean.

\section{H. Workup of the best estimates of $P_{T}$}

Table 7 shows the worksheet for $P_{T}$. For ease of analysis, time-of-day has been converted to a decimal value "DAYS." The mean result for the two coils (the best estimate of $\left.P_{T}\right)$ is tabulated here as " $\left\langle P_{1}, P_{3}\right\rangle$ av" and is the value that appears in the summary, Table 1. The "NOTE" column contains some supplemental information that does not appear in Table 1.

In Table 7 , the $P_{i}$-values that are not enclosed in delimiters are the online values, corrected by the $M_{i}$ of Table 3. The $P_{1}$-values enclosed in "(...)" are the online la-values corrected by the combined factor $\mathrm{M}_{1} / 1.0036$ (see Sec. E). Where online efs-data for coil 3 are lacking, the $P_{3}$-values enclosed in " $\{\ldots\}$ " have been estimated from the corresponding sfs-data by assuming the same relative amount of decay as measured on coil 1 (see Sec. F). In a few instances during the polarization buildups, the $P_{3}$-values enclosed in " $\{\{\ldots\}\}$ " have been inferred from the NMR chart- 
Table 7: Target polarization worksheet.

\begin{tabular}{|c|c|c|c|c|c|c|}
\hline DATE-TIME & DAYS & RUN & CORR. $P_{1}$ & CORR. $P_{3}$ & $\left\langle P_{1}, P_{3}\right\rangle_{a v}$ & NOTE \\
\hline $\begin{array}{r}11-\text { May-0430 } \\
1230\end{array}$ & $\begin{array}{l}11.188 \\
11.521\end{array}$ & 125 start & -.788 & -.781 & $\begin{array}{c}-.784 \\
\langle .784\rangle\end{array}$ & sfs \\
\hline 1540 & 11.653 & 127 end & -.782 & -.781 & -.784 & efs \\
\hline 1920 & 11.806 & & +.611 & +.633 & +.622 & nlo \\
\hline 1940 & 11.819 & 129 start & .654 & & $\langle .657\rangle$ & nla \\
\hline 1950 & 11.826 & & .668 & .668 & .668 & nla \\
\hline 2010 & 11.840 & & .681 & .688 & .685 & nla \\
\hline 2040 & 11.801 & $\$ 29$ end & .684 & .685 & .684 & sfs \\
\hline 2120 & 11.889 & 130 start & $(.681)$ & & {$[.677]$} & \\
\hline $12-$ May-0250 & 12.118 & 135 end & $(.676)$ & & {$[.675]$} & \\
\hline 1000 & 12.417 & 141 start & $(.674)$ & & {$[.673]$} & \\
\hline 1710 & 12.715 & 143 end & $(.672)$ & & {$[.671]$} & \\
\hline 1800 & 12.750 & 144 start & $(.672)$ & & {$[.671]$} & \\
\hline 2140 & 12.903 & 146 end & $(.671)$ & & {$[.670]$} & \\
\hline 2330 & 12.979 & & +.673 & +.664 & $+.669^{\circ}$ & efs \\
\hline 15-May- 1620 & 15.681 & & -.835 & -.822 & -.829 & sfs \\
\hline 1650 & 15.701 & & $(.827)$ & & $\langle .821\rangle$ & (high \\
\hline 2330 & 15.979 & 147 start & $(.805)$ & & {$[.796]$} & temperature) \\
\hline 16-May-0650 & 16.285 & 153 end & $(.802)$ & & {$[.793]$} & \\
\hline 1330 & 16.563 & 156 start & $(.800)$ & & {$[.790]$} & \\
\hline 1930 & 16.813 & 160 start & $(.797)$ & & {$[.788]$} & \\
\hline $17-$ May- 0220 & 17.097 & 165 start & $(.796)$ & & {$[.785]$} & \\
\hline 0850 & 17.368 & 169 end & $(.791)$ & & {$[.782]$} & \\
\hline 0920 & 17.389 & & $-.791^{\circ}$ & -.773 & -.782 & efs \\
\hline 1650 & 17.701 & 170 start & +.751 & +.767 & +.759 & nla \\
\hline 1720 & 17.722 & 170 end & .751 & .767 & .759 & sfs(nla) \\
\hline 1810 & 17.757 & 171 end & & & $\langle .758\rangle$ & nla \\
\hline 2300 & 17.958 & & .737 & .764 & .751 & nla \\
\hline 2340 & 17.986 & 172 start & & & $\langle .751\rangle$ & nlo \\
\hline 18-May-0200 & 18.083 & 175 start & & & $\langle .749\rangle$ & nla \\
\hline 0310 & 18.132 & & .735 & .761 & .748 & nla \\
\hline 0440 & 18.194 & & .735 & .764 & .750 & nla \\
\hline 0750 & 18.326 & & .737 & .764 & .751 & nla \\
\hline 1010 & 18.424 & & .734 & .761 & .748 & nla \\
\hline 1150 & 18.493 & & .731 & .757 & .744 & nla \\
\hline 1650 & 18.701 & 195 start & .733 & .753 & .743 & nla (replaced \\
\hline 2150 & 18.910 & 188 start & & .743 & {$[.738]$} & nla H4P1 \\
\hline 2230 & 18.938 & & & .745 & {$[.738]$} & $\rightarrow$ la membranes) \\
\hline 2340 & 18.986 & 188 end & $(.723)$ & & {$[.737]$} & \\
\hline $19-$ May-0340 & 19.153 & 191 start & $(.717)$ & & {$[.735]$} & \\
\hline 0850 & 19.368 & 195 end & $(.715)$ & & {$[.732]$} & \\
\hline 1240 & 19.528 & 198 end & $(.716)$ & & {$[.730]$} & \\
\hline 1400 & 19.583 & 199 start & $(.716)$ & & {$[.729]$} & \\
\hline 1640 & 19.694 & 200 start & $(.715)$ & & {$[.727]$} & \\
\hline 2230 & 19.938 & 203 end & $(.714)$ & & {$[.724]$} & \\
\hline 20-May-0600 & 20.250 & 208 start & $(.707)$ & & {$[.720]$} & \\
\hline 1430 & 20.604 & 213 end & $(.705)$ & & {$[.715]$} & \\
\hline
\end{tabular}




\begin{tabular}{|c|c|c|c|c|c|c|}
\hline DATE-TIME & DAYS & RUN & CORR. $P_{1}$ & CORR. $P_{3}$ & $\left\langle P_{1}, P_{3}\right\rangle_{\text {av }}$ & NOTE \\
\hline 20-May-1630 & 20.688 & 215 start & $(.703)$ & & {$[.714]$} & \\
\hline 1830 & 20.771 & 216 end & $(+.702)$ & $\{f \cdot .725\}$ & {$[+.713]$} & efs \\
\hline 1840 & 20.778 & 217 start & +.706 & & $\langle+.713\rangle$ & nla \\
\hline 1930 & 20.813 & 218 start & .722 & & $\langle .729\rangle$ & nla \\
\hline 2240 & 20.944 & 219 end & .770 & .785 & .777 & nla \\
\hline 2320 & 20.972 & 220 start & .774 & .787 & .780 & sfs \\
\hline 21-May-0200 & 21.083 & 223 start & $(.765)$ & & {$[.771]$} & \\
\hline 0830 & 21.354 & 228 start & $(.763)$ & & [.769] & \\
\hline 1420 & 21.597 & 231 end & +.761 & $\{+.774\}$ & {$[+.767]$} & efs \\
\hline 22-May-0240 & 22.111 & & -.471 & -.461 & -.466 & nla \\
\hline 0300 & 22.125 & 234 start & .554 & & $\langle .549\rangle$ & nla \\
\hline 0430 & 22.188 & 235 start & .751 & & $\langle .747\rangle$ & nla \\
\hline 0600 & 22.250 & 235 end & .810 & .802 & .806 & nla \\
\hline 0720 & 22.306 & 236 end & .840 & .831 & .836 & sfs \\
\hline 0730 & 22.313 & 237 start & $(.835)$ & & $\langle .831\rangle$ & \\
\hline 1240 & 22.528 & 239 end & $(.829)$ & & {$[.827]$} & \\
\hline 1320 & 22.556 & 240 start & $(.829)$ & & {$[.827]$} & \\
\hline 1940 & 22.819 & 243 start & $(.826)$ & & {$[.824]$} & \\
\hline 23-May-0200 & 23.083 & 247 end & $(.825)$ & & {$[.821]$} & \\
\hline 0800 & 23.333 & 251 end & $(-.822)$ & $\{-.813\}$ & {$[-.818]$} & efs \\
\hline 5-Jun-0230 & 5.104 & 252 start & +.774 & +.778 & +.776 & nla \\
\hline 0330 & 5.146 & & .780 & .788 & .784 & sfs(nla) \\
\hline 0350 & 5.160 & 252 end & & & $\langle .784\rangle$ & nla \\
\hline 0520 & 5.222 & 253 end & & & $\langle .785\rangle$ & nla \\
\hline 1150 & 5.493 & & .785 & .793 & .789 & nla \\
\hline 1450 & 5.618 & 254 start & .779 & .786 & .783 & nla \\
\hline 1700 & 5.708 & 255 end & & & $\langle .776\rangle$ & nla \\
\hline 1810 & 5.757 & & .769 & .775 & .772 & nla \\
\hline 1930 & 5.813 & 256 start & & & {$[.782]$} & nla \\
\hline 2020 & 5.847 & 256 end & & .791 & {$[.782]$} & nla \\
\hline 2130 & 5.896 & & $(.783)$ & & {$[.782]$} & $\rightarrow$ la \\
\hline 6-Jun-0] 10 & 6.049 & 257 start & $(.777)$ & & {$[.781]$} & \\
\hline 0550 & V. 243 & 259 end & $(.776)$ & & {$[.780]$} & \\
\hline 0640 & 6.278 & "547" end & $(.776)$ & & {$[.780]$} & \\
\hline 1200 & 6.500 & 261 start & $(.779)$ & & {$[.779]$} & \\
\hline 1710 & 6.715 & 265 start & $(.777)$ & & {$[.779]$} & \\
\hline 1840 & 6.778 & 266 end & $(.776)$ & & {$[.778]$} & \\
\hline 2100 & 6.875 & 267 start & $(.767)$ & & {$[.778]$} & \\
\hline 7-Jun-0200 & 7.083 & 270 start & $(.771)$ & & {$[.777]$} & \\
\hline 0840 & 7.361 & 273 end & $(.773)$ & & {$[.776]$} & \\
\hline 1410 & 7.590 & 277 end & $(.775)$ & & {$[.775]$} & \\
\hline 1650 & 7.701 & & +.772 & +.778 & +.775 & efs \\
\hline 1920 & 7.806 & & -.740 & -.673 & -.707 & nla \\
\hline 2010 & 7.840 & 279 start & .794 & & $\langle .768\rangle$ & nla \\
\hline 2120 & 7.889 & 280 start & .823 & .777 & .800 & sfs \\
\hline 2200 & 7.917 & & $(.818)$ & & {$[.794]$} & \\
\hline 8-Jun-0450 & 8.201 & 285 start & $(.812)$ & & {$[.790]$} & \\
\hline 1310 & 8.549 & 289 end & $(.812)$ & & {$[.785]$} & \\
\hline
\end{tabular}




\begin{tabular}{|c|c|c|c|c|c|c|}
\hline DATE-TIME & DAYS & RUN & CORR. $P_{1}$ & CORR. $P_{3}$ & $\left\langle P_{1}, P_{3}\right\rangle_{a v}$ & NOTE \\
\hline 8-Jun-2010 & 8.840 & 297 end & $(.800)$ & & {$[.781]$} & \\
\hline 9-Jun-0350 & 9.160 & 302 end & $(.795)$ & & {$[.776]$} & \\
\hline 0520 & 9.222 & 303 start & $(.795)$ & & {$[.776]$} & \\
\hline 1200 & 9.500 & 308 start & $(.801)$ & & {$[.772]$} & \\
\hline 1620 & 9.681 & 310 end & $(.792)$ & & {$[.769]$} & \\
\hline 1650 & 9.701 & 311 end & $(-.791)$ & $\{-.747\}$ & {$[-.769]$} & efs \\
\hline 10 -Jun-0550 & 10.243 & & +.745 & +.756 & +.751 & nla \\
\hline 0640 & 10.278 & 319 start & .766 & & $\langle .765\rangle$ & nla \\
\hline 0710 & 10.299 & & .776 & .767 & .772 & nla \\
\hline 0740 & 10.319 & & .778 & .770 & .774 & sfs \\
\hline 0800 & 10.333 & 320 start & $(.769)$ & & {$[.774]$} & \\
\hline 1450 & 10.618 & 325 start & $(.768)$ & & {$[.774]$} & \\
\hline 2240 & 10.944 & 328 end & $(.767)$ & & {$[.774]$} & \\
\hline $11-$ Iun-0010 & 11.007 & 329 end & $+.776^{\prime}$ & +.771 & +.774 & efs \\
\hline 0120 & 11.056 & 330 start & -.737 & $\{\{-.707\}\}$ & $\langle-.722\rangle$ & nla \\
\hline 0150 & 11.075 & 330 end & .799 & $\{\{.769\}\}$ & $\langle .784\rangle$ & nla \\
\hline 0210 & 11.090 & 331 start & .798 & .787 & .793 & sfs \\
\hline 0225 & 11.101 & & $(.797)$ & & $\langle .792\rangle$ & \\
\hline 0720 & 11.306 & 336 start & $(.785)$ & & {$[.785]$} & \\
\hline 1410 & 11.590 & 339 end & $(.781)$ & & {$[.783]$} & \\
\hline 1530 & 11.646 & 340 start & $(.780)$ & & {$[.782]$} & \\
\hline 2100 & 11.875 & 343 end & $(.776)$ & & {$[.780]$} & \\
\hline $12-J u n-0200$ & 12.083 & 348 end & $(.772)$ & & {$[.779]$} & \\
\hline 0440 & 12.194 & 349 start & $(.769)$ & & {$[.778]$} & \\
\hline 0650 & 12.285 & 350 end & $(.768)$ & & {$[.777]$} & \\
\hline 1140 & 12.486 & & $(.766)$ & & {$[.775]$} & \\
\hline 2000 & 12.833 & & $(.763)$ & & {$[.772]$} & \\
\hline $13-J u n-0400$ & 13.167 & & $(.760)$ & & {$[.769]$} & \\
\hline 1200 & 13.500 & & $(.769)$ & & {$[.766]$} & \\
\hline 2000 & 13.833 & & $(.765)$ & & {$[.764]$} & \\
\hline $14-J u n-0400$ & 14.167 & & $(.758)$ & & {$[.761]$} & \\
\hline 1120 & 14.472 & 351 start & $(.756)$ & & {$[.758]$} & \\
\hline 1850 & 14.785 & 355 end & $(.751)$ & & {$[.755]$} & \\
\hline 15-Jun-0010 & 15.007 & 359 start & $(.749)$ & & {$[.754]$} & \\
\hline 0550 & 15.243 & 362 end & $(.745)$ & & {$[.752]$} & \\
\hline 0630 & 15.271 & 363 start & $(.745)$ & & {$[.751]$} & \\
\hline 1430 & 15.604 & 369 end & $(.742)$ & & {$[.748]$} & \\
\hline 1500 & 15.625 & 370 end & $(.742)$ & & {$[.748]$} & \\
\hline 1540 & 15.653 & & .746 & .750 & $.748^{\circ}$ & nla \\
\hline 1720 & 15.722 & 371 start & & & $\langle .746\rangle$ & nla \\
\hline 2000 & 15.833 & 373 end & & & $\langle .742\rangle$ & nla \\
\hline 2330 & 15.979 & & -.733 & -.741 & -.737 & efs \\
\hline 16 -Jun- 0250 & 16.118 & 374 start & +.798 & +.813 & +.805 & nla \\
\hline 0310 & 16.132 & 375 start & & & $\langle .805\rangle$ & sfs \\
\hline 0340 & 16.153 & 377 start & $(.789)$ & & {$[.799]$} & \\
\hline 0850 & 16.368 & 380 end & $(.785)$ & & {$[.795]$} & \\
\hline 1430 & 16.604 & 383 end & $(.777)$ & & {$[.790]$} & \\
\hline 1810 & 16.757 & 384 start & $(.765)$ & & {$[.787]$} & \\
\hline
\end{tabular}




\begin{tabular}{|c|c|c|c|c|c|c|}
\hline DATE-TIME & DAYS & RUN & CORR. $P_{1}$ & CORR. $P_{3}$ & $\left\langle P_{1}, P_{3}\right\rangle_{a v}$ & NOTE \\
\hline 17-Jun-0030 & 17.021 & 387 end & $(.767)$ & & {$[.781]$} & \\
\hline 0730 & 17.313 & 392 start & $(.761)$ & & {$[.775]$} & \\
\hline 1210 & 17.507 & & $(.761)$ & & {$[.771]$} & \\
\hline 1350 & 17.576 & 395 end & +.760 & +.779 & +.770 & efs \\
\hline 1810 & 17.757 & 399 start & -.807 & -.796 & -.801 & sfs \\
\hline 1820 & 17.764 & & $(.804)$ & & $\langle .798\rangle$ & \\
\hline 2150 & 17.910 & 400 start & $(.798)$ & & {$[.792]$} & \\
\hline $18-J u n-0310$ & 18.132 & 402 end & $(.792)$ & & {$[.790]$} & \\
\hline 0840 & 18.361 & 405 end & $(.788)$ & & {$[.787]$} & \\
\hline 1210 & 18.507 & 407 end & $(.788)$ & & {$[.785]$} & \\
\hline 2000 & 18.833 & & $(.781)$ & & {$[.781]$} & (replaced H4P2 \\
\hline 19-Jun-0400 & 19.167 & & $(.779)$ & & {$[.776]$} & membrane) \\
\hline 1220 & 19.514 & & $(.774)$ & & {$[.772]$} & \\
\hline 1800 & 19.750 & & -.774 & $\{-.763\}$ & {$[-.769]$} & efs \\
\hline 20-Jun-0310 & 20.132 & & +.708 & +.734 & +.721 & nla \\
\hline 0450 & 20.201 & 408 start & .768 & & $\langle .759\rangle$ & nla \\
\hline 0610 & 20.257 & 408 end & .778 & $\langle .763\rangle$ & $\langle .770\rangle$ & sfs \\
\hline 0700 & 20.292 & 409 start & $(.773)$ & & {$[.764]$} & \\
\hline 0900 & 20.375 & & .770 & .755 & .762 & (brief nla) \\
\hline 1400 & 20.583 & 412 start & $(.769)$ & & {$[.761]$} & \\
\hline 1910 & 20.799 & 415 end & $(.769)$ & & {$[.759]$} & \\
\hline 2120 & 20.889 & 416 start & $(.767)$ & & {$[.758]$} & \\
\hline $21-J u n-0210$ & 21.090 & 418 end & $(.765)$ & & {$[.757]$} & \\
\hline 0730 & 21.313 & 422 end & $(.767)$ & & {$[.755]$} & \\
\hline 0930 & 21.396 & 424 start & $(.763)$ & & {$[.754]$} & \\
\hline 1740 & 21.736 & 428 end & $(.760)$ & & {$[.751]$} & \\
\hline 1810 & 21.757 & & +.757 & +.745 & +.751 & efs \\
\hline 23-Jun-0930 & 23.396 & 450 start & -.411 & $\{\{-.301\}\}$ & $\langle-.356\rangle$ & nla \\
\hline 1100 & 23.458 & 451 start & .567 & & $\langle .512\rangle$ & nla \\
\hline 1240 & 23.528 & 452 start & .658 & & $\langle .603\rangle$ & nla \\
\hline 1320 & 23.556 & 453 start & .671 & & $\langle .616\rangle$ & nla \\
\hline 1420 & 23.597 & 454 start & .695 & & $\langle .640\rangle$ & nla \\
\hline 1530 & 23.646 & & .717 & .607 & .662 & nla \\
\hline 1600 & 23.667 & 454 end & .722 & .622 & .672 & sfs \\
\hline 1620 & 23.681 & 455 start & $(.710)$ & & {$[.660]$} & \\
\hline 2140 & 23.903 & 458 start & $(.706)$ & & {$[.657]$} & \\
\hline 24-Jun-0430 & 24.188 & 462 start & $(.703)$ & & {$[.654]$} & \\
\hline 1200 & 24.500 & 465 end & $(.699)$ & & {$[.650]$} & \\
\hline 1830 & 24.771 & 469 end & $(.696)$ & & {$[.647]$} & \\
\hline 2140 & 24.903 & & $(.693)$ & & {$[.645]$} & \\
\hline $25-J u n-0000$ & 25.000 & 472 end & -.692 & $\{-.596\}$ & {$[-.644]$} & efs \\
\hline 0040 & 25.028 & 473 start & -.753 & & $\langle-.724\rangle$ & nla \\
\hline 0210 & 25.090 & 473 end & .818 & .800 & .809 & sfs \\
\hline 0350 & 25.160 & 474 end & $(.808)$ & & [.799] & \\
\hline 0520 & 25.222 & 475 end & $(-.806)$ & $\{-.788\}$ & {$[-.797]$} & efs \\
\hline 0600 & 25.250 & 476 start & -.233 & & $\langle-.230\rangle$ & nla \\
\hline 0720 & 25.306 & 477 start & .612 & & $\langle .604\rangle$ & nla \\
\hline
\end{tabular}




\begin{tabular}{|c|c|c|c|c|c|c|}
\hline DATE-TIME & DAYS & RUN & CORR. $P_{1}$ & CORR. $P_{3}$ & $\left\langle P_{1}, P_{3}\right\rangle_{a v}$ & NOTE \\
\hline $25-J u n-0810$ & 25.340 & & .761 & .741 & .751 & nla \\
\hline 0840 & 25.361 & 478 start & .798 & & $\langle .795\rangle$ & nla \\
\hline 1000 & 25.417 & 479 end & .822 & .826 & .824 & sfs \\
\hline 1130 & 25.479 & 480 start & $(.816)$ & & [.819] & \\
\hline 1520 & 25.639 & 485 end & $(.814)$ & & {$[.817]$} & \\
\hline 1540 & 25.653 & 486 start & $(.814)$ & & {$[.817]$} & \\
\hline 2310 & 25.965 & 490 start & $(.807)$ & & {$[.813]$} & \\
\hline 26-Jun-0750 & 26.326 & 494 end & $(.805)$ & & {$[.809]$} & \\
\hline 1300 & 26.542 & & $(.804)$ & & {$[.806]$} & \\
\hline 1810 & 26.757 & 495 start & $(.803)$ & & {$[.804]$} & \\
\hline $27-J u n-0150$ & 27.076 & 499 end & $(.796)$ & & {$[.800]$} & \\
\hline 1040 & 27.444 & 500 end & $(.793)$ & & {$[.796]$} & \\
\hline 1210 & 27.507 & 507 start & $(.792)$ & & {$[.795]$} & \\
\hline 1440 & 27.611 & 508 end & $(.790)$ & & {$[.794]$} & \\
\hline 1950 & 27.826 & 509 start & $(.787)$ & & {$[.791]$} & \\
\hline 2200 & 27.917 & 510 end & $(.786)$ & & {$[.790]$} & \\
\hline 2220 & 27.931 & & -.788 & -.793 & $-.790^{\circ}$ & efs \\
\hline 2350 & 27.993 & 511 start & +.274 & & $\langle+.275\rangle$ & nla \\
\hline 28-Jun-0200 & 28.083 & & .757 & .763 & .760 & nla \\
\hline 0210 & 28.090 & 511 end & .759 & & $\langle .761\rangle$ & nla \\
\hline 0230 & 28.104 & 512 start & .765 & & $\langle .764\rangle$ & nla \\
\hline 0300 & 28.125 & 513 start & .766 & .764 & .765 & sfs \\
\hline 0310 & 28.132 & & $(.763)$ & & $\langle .762\rangle$ & \\
\hline 0350 & 28.160 & & $(.758)$ & & {$[.753]$} & \\
\hline 1140 & 28.486 & 518 end & $(.753)$ & & {$[.750]$} & \\
\hline 1230 & 28.521 & 519 start & $(.753)$ & & {$[.750]$} & \\
\hline 1820 & 28.764 & 522 start & $(.751)$ & & {$[.747]$} & \\
\hline 29-Jun-0020 & 29.014 & 526 start & $(.748)$ & & {$[.745]$} & \\
\hline 0750 & 29.326 & 530 end & $(.746)$ & & {$[.743]$} & \\
\hline 1240 & 29.528 & 531 start & $(.744)$ & & {$[.741]$} & \\
\hline 1930 & 29.813 & 536 start & $(.742)$ & & {$[.738]$} & \\
\hline $30-J$ un- 0200 & 30.083 & 539 end & $(.740)$ & & {$[.736]$} & \\
\hline 0300 & 30.125 & 540 start & $(.739)$ & & {$[.736]$} & \\
\hline 0800 & 30.333 & 542 end & $(.738)$ & & {$[.734]$} & \\
\hline 0920 & 30.389 & 543 start & $(.737)$ & & {$[.734]$} & \\
\hline 1120 & 30.472 & 545 start & $(.737)$ & & {$[.733]$} & \\
\hline 1300 & 30.542 & 546 start & $(.737)$ & & {$[.732]$} & \\
\hline 1840 & 30.778 & 546 end & $(.736)$ & & {$[.730]$} & \\
\hline $1-J u l-0230$ & 1.104 & 551 end & $(.732)$ & & {$[.727]$} & \\
\hline 0910 & 1.382 & 554 end & $(.729)$ & & {$[.725]$} & \\
\hline 1200 & 1.500 & 556 end & $+.725^{\prime}$ & +.724 & +.724 & efs \\
\hline 1510 & 1.632 & & -.797 & -.800 & -.798 & sfs \\
\hline 1530 & 1.646 & 557 start & $(.793)$ & & $\langle .794\rangle$ & \\
\hline 2010 & 1.840 & 559 start & $(.786)$ & & {$[.793]$} & \\
\hline $2-J u l-0220$ & 2.097 & 560 end & $(.783)$ & & {$[.787]$} & \\
\hline 0810 & 2.340 & 562 end & $(.777)$ & & {$[.782]$} & \\
\hline 0820 & 2.347 & & -.778 & -.787 & -.782 & efs \\
\hline
\end{tabular}


recorder trends. The values of $\left\langle P_{1}, P_{3}\right\rangle_{a v}$ enclosed in "[...]" were derived by backextrapolating the efs-value using the slope of decay exhibited by the corresponding $P_{1}$-measurements (see Table 6). The remaining values of $\left\langle P_{1}, P_{3}\right\rangle_{\text {av }}$ enclosed in "(...)" are interpolations of the surrounding data, mainly nla-measurements taken during the buildups.

\section{Error estimates}

The estimated total uncertainty on the polarization is $\pm 6.5 \%$, consisting of the following contributions:
a) Temperature of thermals
$4.5 \%$
b) Statistical uncertainties of thermals
$1.5 \%$
c) NMR background
$1.0 \%$
d) Spatial uniformity of polarization
$3.0 \%$
e) NMR nonlinearity
$1.0 \%$
f) Residual NMR drift
$2.2 \%$
g) Errors of interpolation/extrapolation
$2.0 \%$

These contributions are (mostly) symmetric and uncorrelated, so they have been added in quadrature. Contribution (a) arises from uncertainty in the thermometer lead resistance and calibration of the thermometry software. Contribution (b) is typical for the $2 \sigma$ errors of Table 2. Contribution (c) is based on past experience with clean target-holder structures made of Teflon. Concerning contribution (d), as was seen in Sec. D, the global averages of the peak polarizations measured on the two end coils are in close agreement, $\left\langle\left|P_{1}\right|\right\rangle=0.796 \pm 0.006$ vs $\left\langle\left|P_{3}\right|\right\rangle=0.793 \pm 0.006$. Differences of $10 \%$ or more between the two coils were sometimes seen during buildups, however, these observable differences are accounted for in Table 1 by the averaging of the results for the two coils. The additional allowance of $3 \%$ is included above mainly in consideration of the fact that data from the center NMR coil were unavailable. Contribution (e) is known to be typical for NMR detectors of the Liverpool type. Contributions ( $f$ ) and $(\mathrm{g})$ are estimated from the levels of internal consistency of the results.

Note that the first three contributions are pure scaling errors on $\mathrm{P}_{\mathrm{T}}$. Therefore, at least for the purpose of comparisons within a given "thermals" period, and to a considerable extent even globally, these uncertainties do not contribute to the error analysis for measurements that depend only on the ratio of the two signs of polarization, $\mathrm{P}_{\mathrm{T}}(+) / \mathrm{P}_{\mathrm{T}}(-)$. The estimated total uncertainty on the ratio is thus $\pm 4.3 \%$.

It should be stressed that all of the above uncertainties are considered to be " $2 \sigma$ " estimates, i.e., they represent the maximum likely excursions. 

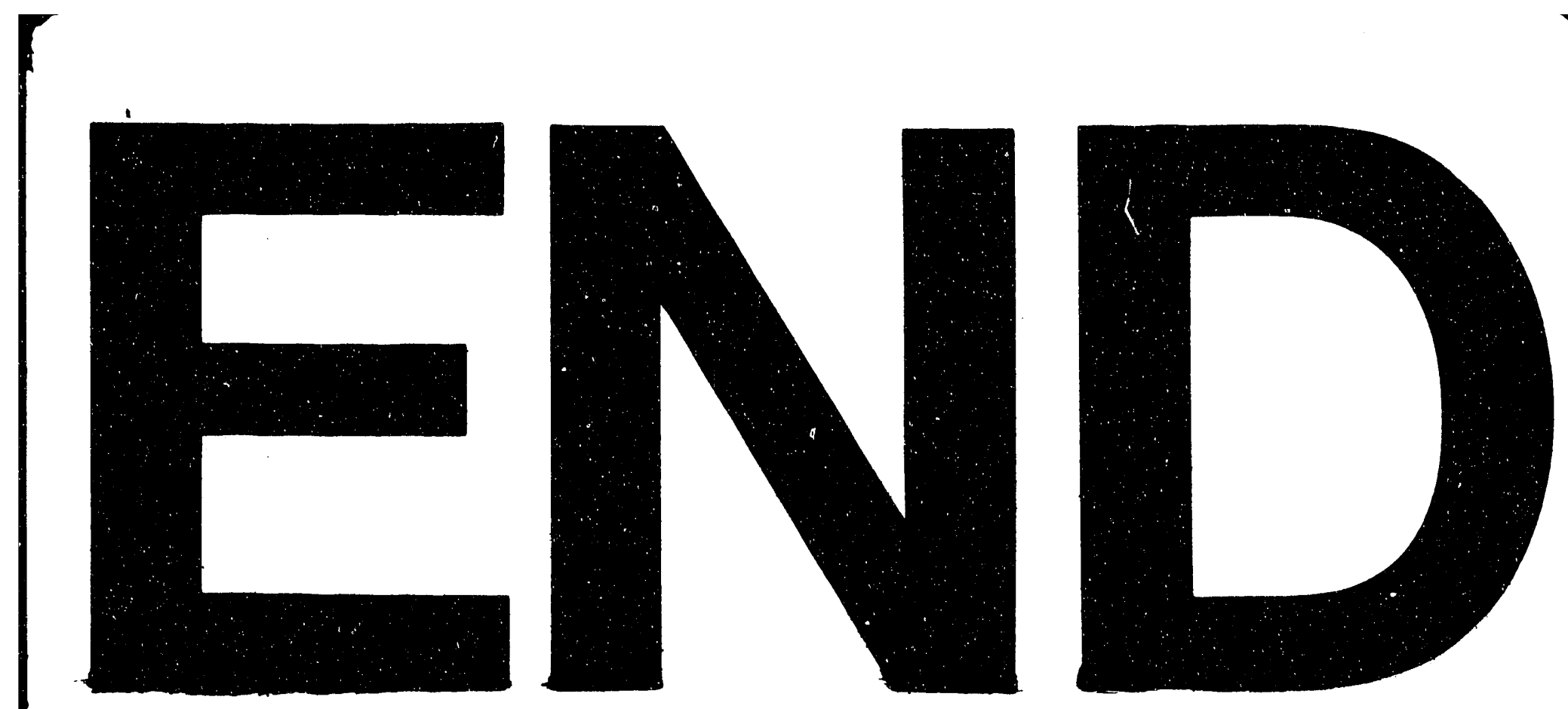

$\nabla$
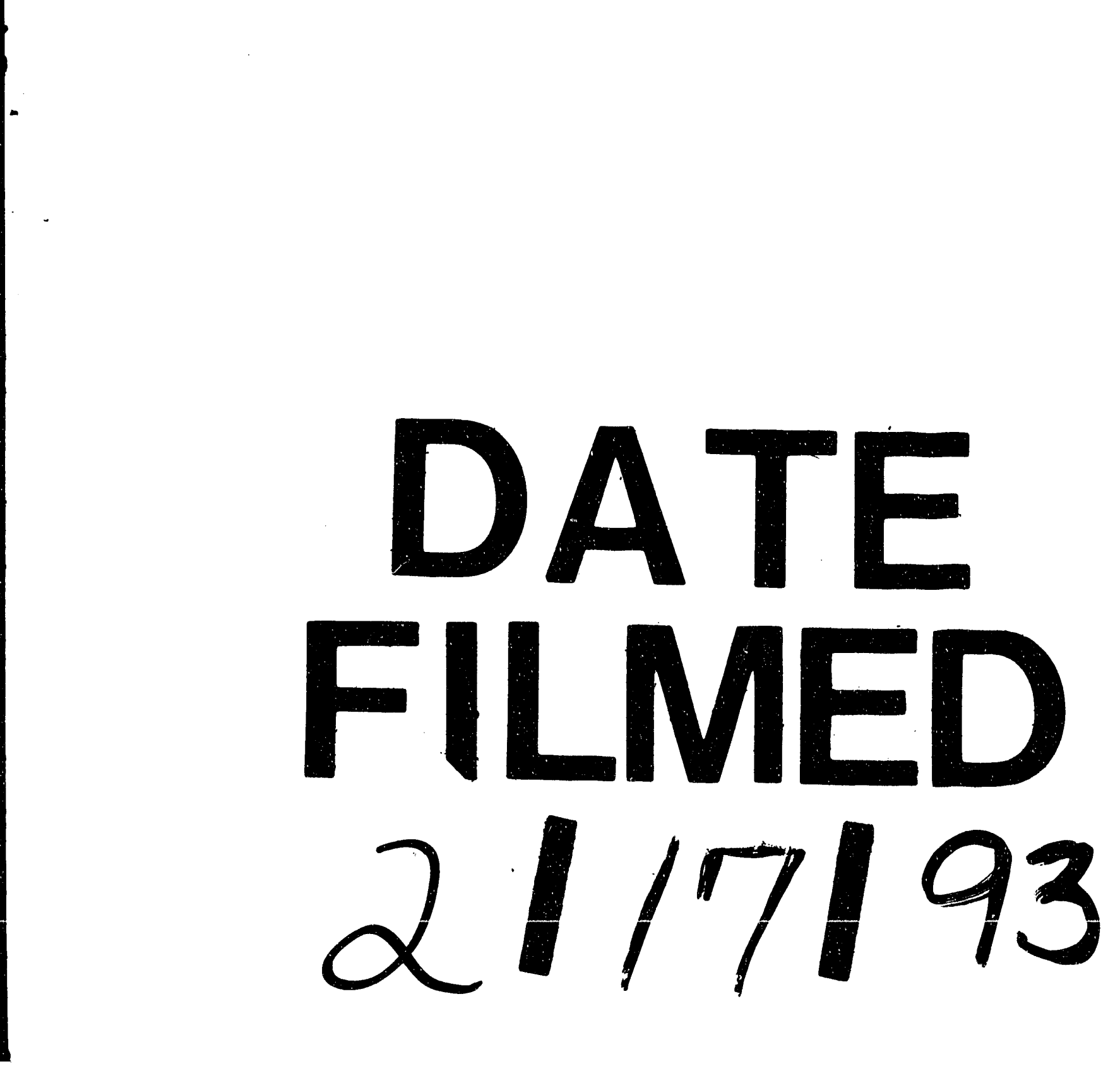


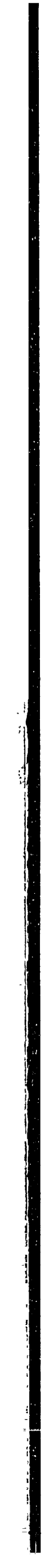

